\title{
Impact of a physical activity program on plasma concentrations of adiponectin, leptin and ghrelin in overweight and obese schoolchildren: A randomized controlled trial
}

\author{
André Everton de Freitas ${ }^{1,2^{\star}}$, Joel Alves Lamounier ${ }^{3}$, Danusa Dias Soares ${ }^{4}$, \\ Thiago Henrique de Oliveira $^{1}$, Débora Romualdo Lacerda ${ }^{4}$, Joyce Batista Andrade ${ }^{1}$, \\ Flávia Komatsuzaki ${ }^{1}$, Leida Maria Botion ${ }^{5}$, Adaliene Versiani Matos Ferreira ${ }^{6}$, \\ Camilo Adalto Mariano da Silva ${ }^{7}$, Dilermando Fazito Rezende ${ }^{8}$ \\ ${ }^{1}$ Graduate Program in Child and Teenager Health, Medicine School, Federal University of Minas Gerais, Belo Horizonte, Brazil \\ ${ }^{2}$ Faculty of Health and Human Ecology, Medicine School, Vespasiano, Brazil; \\ *Corresponding Author: aefreitas@yahoo.com \\ ${ }^{3}$ Graduate Program in Health Sciences, Medicine School, Federal University of São João Del Rei, Campus Midwest, Divinópolis, Brazil \\ ${ }^{4}$ Laboratory of Exercise Physiology, Federal University of Minas Gerais, Belo Horizonte, Brazil \\ ${ }^{5}$ Laboratory of Metabolism, Federal University of Minas Gerais, Belo Horizonte, Brazil \\ ${ }^{6}$ School of Nursing, Federal University of Minas Gerais, Belo Horizonte, Brazil \\ ${ }^{7}$ School of Nutrition, Federal University of Ouro Preto, Ouro Preto, Brazil \\ ${ }^{8}$ Faculty of Medicine Barbacena, Barbacena, Brazil
}

Received 18 August 2013; revised 18 September 2013; accepted 1 October 2013

Copyright (C) 2013 André Everton de Freitas et al. This is an open access article distributed under the Creative Commons Attribution License, which permits unrestricted use, distribution, and reproduction in any medium, provided the original work is properly cited.

\section{ABSTRACT}

Introduction: Child obesity has important consequences on the child's health and is related to the risk of developing chronic diseases. That brings up the need for research assessing the impact of obesity- and overweight-reduction programs with close attention to methodology aspects and precise indicators of the impact of such programs. Goal: Assessing the impact of a physical activity program on the plasma concentrations of adiponectin, leptin, and ghrelin in overweight and obese schoolchildren. Methods: Randomized controlled trial, double-blind, with 6- to 9-year-old overweight and obese schoolchildren. A sample of 79 schoolchildren randomly distributed into control and intervention groups was subjected to a physical activity program. The levels of adiponectin, leptin, ghrelin, body mass index, body fat percentage, anthropometry, lipid profile and glycemia were evaluated. The program's impact was assessed through multivariate linear regression models. Result: When comparing the groups, a significant difference was found for adiponectin, which shows an increase in the proportion of subjects with higher adiponectin concentrations for the intervention group and a reduction in body mass index and body fat percentage. Conclusion: The impact of the intervention program was positive in increasing adiponectin levels associated with a reduction in body mass index and body fat percentage.

Keywords: Obesity; Overweight; Schoolchildren; Physical Activity; Adipocitokines

\section{INTRODUCTION}

Population studies show that excess fatty tissue, mainly in the abdominal region, is closely related to the risk of developing coronary artery disease, systemic arterial hypertension, diabetes mellitus, and dyslipidemias and that this association grows as BMI increases [1-3]. Most of these diseases are related to the action of the fatty tissue as an endocrinal organ since the adipocytes synthesize several substances such as adiponectin, glucocorticoids, tumor necrosis factor (TNF- $\alpha$ ), sexual hormones, interleukin 6 (IL-6), and leptin, which act in the energy balance, metabolism, control of several systems, and the obesity-derived complications [4].

The effectiveness of the interventions on the obesity 
epidemic requires multiple strategies to be added up involving all social groups, as well as individuals [5]. Increasing physical activity may be an important factor to optimize reductions in abdominal fat, especially visceral fat, in overweight children [6]. Healthy eating habits during pregnancy, along with an active lifestyle of children and teenagers, may be important factors in the prevention of long-term risk of obesity $[7,8]$.

Besides preventing several diseases such as obesity, diabetes, and hypertension, physical activity also entitles children to have leisure activities for social integration and development of skills, which leads to greater selfesteem and confidence [9].

Summerbell et al. [10] concluded that the researches focusing on the combination of diet and physical activity did not show a significant change in BMI, while intervening with either diet or physical activity had a positive impact on BMI. They also ruled out the importance of the involvement of the family, schools, community, and environment in the obesity prevention process and appropriate study design and adequate control of the duration and intensity of the interventions.

The literature highlights the need for researches for assessing the impact of child obesity and overweight reduction programs. Thus, in a set of changes in the nutritional problem patterns, with the increasing prevalence of obesity and its repercussions on health, the current study aimed to assess the impact of a physical activity program on the plasma concentration of adiponectin, leptin, and ghrelin in overweight and obese students.

\section{METHODS}

The current research is a double-blind, randomized controlled trial with overweight and obese students between six and nine years old enrolled in seven urban public schools in the city of Ouro Preto, Minas Gerais state, Brazil. The schools were chosen following the criteria of being within the urban area and of having areas for the practice of physical activities. The children selected were between six and nine years old who were either overweight or obese in good health (able to practice physical activities) and who were enrolled in the morning or afternoon shifts of public schools in the urban area of the city of Ouro Preto from pre-school to fourth grade. The schools with night shifts and the children between six and nine years old with chronic illnesses were excluded.

The study population included 1019 students according to the data provided by the Municipal Secretary of Education and the schools' registry. In order to calculate the initial sample, the prevalence of overweight and obesity was identified in this population. All children identified as being overweight or obese were invited to take part of the study. The sample was made up of 79 children whose parents and/or guardians authorized their participation. The children eligible to the study were distributed in a random, blind, and concealed way into two groups: intervention (A) and control (B) Figure 1 illustrates the

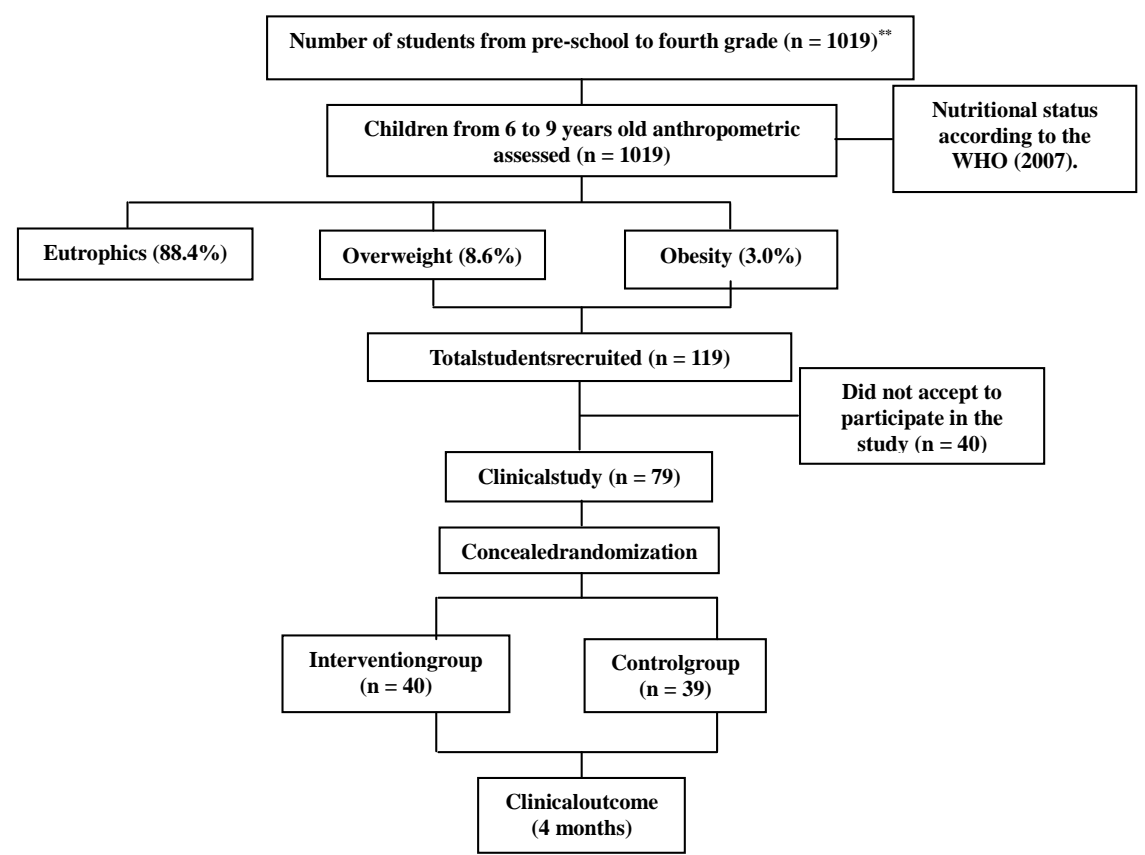

Figure 1. Distribution of the children into two groups: intervention (A) and control (B). ** total number of students enrolled from pre-school to fourth grade in seven urban schools of Ouro Preto, MG, according to the roll call list provided by the schools' principals. 
steps involved:

The study assessments were carried out in the morning. For all data collection, a protocol for standardizing the collection procedures was created and all the researchers were previously selected and trained on the research procedures. Before beginning the intervention program, all children allocated to the control and intervention groups underwent an initial evaluation and baseline data were collected for the following parameters:

- Anthropometric data: Weight and height for calculating the BMI, which was calculated from the ratio between total body weight in kilograms and the squared height in meters (Quetelet index) [11]. The cut-off points indicated by the WHO (2007) [12] were used. An Alturaexata ${ }^{\circledR}$ vertical anthropometer and a TANITA BF599 electronic digital scale were employed.

- Waist and hip circumference: A two-meter tape measure was used and the cut-off points proposed by Taylor et al. (2000) [13] were adopted. The waist-hip ratio (WHR) was obtained by dividing the waist circumference by the hip circumference.

- Skinfold thickness (SK): A Lange Skinfold Caliper was used to measure skinfold thickness (triceps and calf) with a scale from 0 to $60 \mathrm{~mm}$ and $\pm 1 \mathrm{~mm}$ precision according to the techniques recommended by Heyward et al. (2000) [14]. The equation proposed by Slaughter et al. (1988) [15] was adopted to evaluate the body fat percentage (BF \%).

- Biochemical variable: All blood samples were collected at the schools in the morning (between 7:00 and 9:00 AM). $6 \mathrm{~mL}$ were collected from each child per sample, which were then centrifuged and stored at $-20^{\circ} \mathrm{C}$. All children were instructed to remain in fasting for 12 hours. The colorimetric method (Labtest ${ }^{\circledR}$ ) was used for analyses of glycemia and lipid profile (total cholesterol, HDL, LDL, and triglyceride). LDL was estimated based on the equation proposed by Friedewald, Levy, and Fredrickson (1972) [16]. The ELISA (Linco Research) method was used for analyses of adiponectin, leptin, and ghrelin [17-19].

\subsection{Intervention Program}

After the initial data collection, the intervention program began, which lasted for four months. All the subjects selected and randomly allocated to either the control or intervention groups were part of an intervention program developed as follows:

Control group $(n=39)$ : The children allocated and their parents and/or guardians attended a series of lectures on healthy eating habits, practice of physical activities, and family relations over the four-month period. The program had two lectures a month, one for the parents and another for the children, for a total of eight events. The lectures comprised workshops and educa- tional projects in Nutrition in order to stimulate a higher intake of healthy foods and a lower intake of foods with high fats and calorie content. They also included actions promoting healthy habits for reducing sedentarism, aiming at reducing the number of hours using computers, videogames, and similar equipment. At the same time, the children were stimulated to practice more physical activities through individual and team sports.

Intervention group $(n=40)$ : The children allocated underwent a physical activity program three times a week, in the afternoon, for 50 minutes over the fours months of the school semester. The program included recreational activities, collective games, races, and vaults in a covered gymnasium. Moreover, educational lectures were given (to both parents and children) on the same subjects as those for the control group twice a month over the four-month period.

The caloric expenditure and the maximal oxygen uptake $\left(\mathrm{VO}_{2 \max }\right)$ were measured through open-circuit spirometry with a portable metabolic system (COSMED K4). The data were collected from five randomly chosen children from the intervention group during the 50-minute physical activity class included in the intervention program.

After the four months of the intervention period, a new evaluation was performed, by the same researchers, using the previously collected parameters.

\subsection{Data Analysis}

The study data were stored, coded, and analyzed by the softwares EpiInfo 6.2 and MiniTab14. The data compilation and the statistical analysis were performed in a way that the statistician and assessor would be blinded regarding the allocation of volunteers. According to the probability distribution of the data analyzed, from the Shapiro-Wilk test for normality, parametric (t-test and paired t-tests) or non-parametric (Wilcoxon and MannWhitney) tests were applied to the averages of medians when the distribution was considered normal and nonnormal, respectively. The difference was considered statistically significant at a $5 \%$ level $(p \leq 0.05)$.

The program's impact on the plasma concentrations of adiponectin, leptin, and ghrelin in the control and intervention groups was analyzed based on multivariate linear regression models in which the values of these three plasma variables were acquired from the differences between the values after and before the intervention program (four months). The analysis also investigated which variables influenced the values of the plasma variables.

The multivariate models for leptin, ghrelin, and adiponectin of both the control and intervention groups were selected as follows: Initially, a correlation analysis was performed on the variables for the control and intervention groups through Pearson's and Spearman's tests 
(for parametric and non-parametric distribution, respectively) so that the presence of multicollinearity among the variables could be verified. Next, all univariate models were adjusted, i.e., each response variable with the variables individually. From these adjustments, only the variables that had values of $p \leq 0.25$ were selected. After that, the stepwise backward and best subset selection methods (automatic and manual) were applied.

For the analysis comparing the quantitative variables of the groups in the periods prior to and after the intervention, paired t-test and Wilcoxon test were employed for each group individually. In order to compare the control and intervention groups for the pre- and post-intervention periods individually, t-test and Mann-Whitney test were employed.

Aiming to better control the study, the professionals taking part in the study received manuals containing each aspect of the protocol used and were also trained on the procedures and conducts of the research. Randomized distribution, concealed allocation, blinded analysis, and intention-to-treat analysis were adopted in order to minimize bias [20].

\section{RESULTS}

The characteristics of the groups studied were: age average of $7.69 \pm 1.08$ years and BMI of $19.87 \pm 1.81$ $\mathrm{kg} \cdot \mathrm{m}^{-2}$ for the control group and average age of $7.09 \pm$ 1.12 years and BMI of $22.3 \pm 3.17 \mathrm{~kg} \cdot \mathrm{m}^{-2}$ for the intervention group. Table 1 shows the characteristics of the groups studied and the comparison of the result averages pre- and post-intervention $(n=79)$. The reductions in the number of samples that took place for some variables were due to extreme values (outliers), hemolysis of the sample, and the child refusing blood collection. The average caloric expenditure and $\mathrm{VO}_{2 \max }$ during a 50-minute physical activity in the intervention group was $153.38 \pm$ $27.28 \mathrm{kcal}$ and $43.34 \pm 7.28 \mathrm{~mL} \mathrm{O}{ }_{2} \cdot \mathrm{kg}^{-1} \cdot \mathrm{min}^{-1}$, respectively, for a moderate activity.

When comparing the data of the control group between the pre- and post-intervention periods, the following outcomes had a 5\% significance level: weight, BMI, height, and glycemia increased, while skinfold thickness decreased. When comparing the data of the intervention group between the pre- and post-intervention periods, the following results had a 5\% significance level: weight and glycemia increased, skinfold thickness and HDL decreased, and BMI tended to decrease (6\%). A significant difference was found between the groups for weight, $\mathrm{BMI}, \mathrm{BF} \%$, total cholesterol (TC), LDL, triglycerides (TG), glycemia, and adiponectin.

Finally, when comparing the data of the post-intervention period between the control and intervention groups, the results were: Weight, BMI, BF\%, SK, HDL, ghrelin, adiponectin, and $\mathrm{BF} \%$ had no differences; WHR,
TC, TG, LDL, and adiponectin were higher in the intervention group; and glycemia was lower.

The result of the analysis of the program's impact on plasma concentrations of adiponectin, leptin, and ghrelin in the control and intervention groups was analyzed starting with the correlation between the variables studied. Weight, height, and LDL were excluded from the leptin model for the control group. While for the intervention group $\mathrm{BF} \%$ was excluded from the leptin model, TC was excluded from the adiponectin model, and LDL was excluded from the ghrelin model in order to avoid multicollinearity in the regression model. Next, all univariate models were adjusted and only the variables with values of $p \leq 0.25$ were selected and, subsequently, they were automatically selected through the stepwise backward and best subset methods (multivariate linear regression models). In the analyses of the univariate models of the control group for the dependent variables (Table 2), $p \leq 0.25$ significance was reported for sex, $\mathrm{BF} \%$, BMI, SK, TC, and HDL for leptin; HDL for adiponectin; and SK for grhelin. In the univariate models for the intervention group, significance was found for weight, SK, and TC for leptin; weight and LDL for adiponectin; and BMI, TC, and TG for ghrelin.

The models that had the best results altogether were chosen and the residuals analysis was performed to evaluate the assumptions of the linear regression model: The residuals had normal distribution, were shown to be independent (non-correlated), and with constant variance. Tables 3 and 4 show the multivariate results of the control and intervention groups for the dependent variables adiponectin, leptin, and ghrelin.

Regarding the results of the multivariate analysis for the control group (Table 3), in the ghrelin explanatory model only the SK variable had a significant influence, which explains the $10.5 \%$ of variance for ghrelin. In the leptin model, the variables BMI, SK, and TC explained $47.6 \%$ of the variance for leptin. In the adiponectin model, only the HDL variable explained the variance $(9.4 \%)$. The models' parameters were interpreted as follows: For ghrelin, for every unit increased in the difference of SK, there is a 10.44-unit increase in the difference of ghrelin.

For leptin, for every unit increased in the difference of BMI, there is an 8.53-unit increase in the difference of leptin; for every unit increased in the difference of SK, there is a 1.35-unit increase in the difference of leptin; and for every unit increased in the difference of TC, there is a 0.24-unit increase in the difference of leptin. Finally, for adiponectin, for every unit increased in the difference of HDL, there is a 0.30 -unit increase in the difference of adiponectin. For every case mentioned, the remaining model variables are considered constant.

For the intervention group, the results of Table 4 show 
Table 1. Result of comparing the control and intervention groups.

\begin{tabular}{|c|c|c|c|c|c|c|c|c|c|c|}
\hline \multirow{2}{*}{ Variable } & \multirow{2}{*}{ Period } & \multicolumn{4}{|c|}{ Control } & \multicolumn{4}{|c|}{ Intervention } & \multirow{2}{*}{$p^{* *}$} \\
\hline & & Average \pm SD & Median & $\mathbf{n}$ & $p^{*}$ & Average \pm SD & Median & $\mathbf{n}$ & $p^{*}$ & \\
\hline \multirow{2}{*}{ Weight (kgf) } & Pre & $34.92(5.69)$ & 33.90 & \multirow{2}{*}{39} & \multirow{2}{*}{$0.000^{1}$} & $40.70(10.28)$ & 39.3 & \multirow{2}{*}{40} & \multirow{2}{*}{$0.000^{2}$} & $0.007^{4}$ \\
\hline & Post & $38.96(5.30)$ & 37.40 & & & 41.99 (10.77) & 40.9 & & & $0.124^{3}$ \\
\hline \multirow{2}{*}{ BMI $\left(\mathrm{kg} / \mathrm{m}^{2}\right)$} & Pre & $19.87(1.80)$ & 19.40 & \multirow{2}{*}{39} & \multirow{2}{*}{$0.000^{2}$} & $22.30(3.17)$ & 21.3 & \multirow{2}{*}{40} & \multirow{2}{*}{$0.063^{2}$} & $0.004^{4}$ \\
\hline & Post & $20.50(1.75)$ & 20.13 & & & $21.83(3.66)$ & 21.0 & & & $0.115^{4}$ \\
\hline \multirow{2}{*}{ Height $(\mathrm{cm})$} & Pre & $132.15(7.48)$ & 132.90 & \multirow{2}{*}{39} & \multirow{2}{*}{$0.000^{1}$} & $134.60(8.45)$ & 134.4 & \multirow{2}{*}{40} & \multirow{2}{*}{$0.000^{1}$} & $0.176^{3}$ \\
\hline & Post & $137.65(6.87)$ & 137.30 & & & $137.74(8.48)$ & 136.6 & & & $0.963^{3}$ \\
\hline \multirow{2}{*}{$\mathrm{BF} \%$} & Pre & $28.90(5.49)$ & 28.70 & \multirow{2}{*}{39} & \multirow{2}{*}{$0.905^{1}$} & $32.58(6.34)$ & 32.9 & \multirow{2}{*}{40} & \multirow{2}{*}{$0.137^{1}$} & $0.008^{3}$ \\
\hline & Post & $29.06(5.28)$ & 28.70 & & & $31.69(7.03)$ & 31.3 & & & $0.076^{3}$ \\
\hline \multirow{2}{*}{ SK (\%fat) } & Pre & $33.11(6.32)$ & 33.10 & \multirow{2}{*}{39} & \multirow{2}{*}{$0.000^{1}$} & $34.28(7.23)$ & 35.2 & \multirow{2}{*}{40} & & $0.445^{3}$ \\
\hline & Post & $28.48(5.51)$ & 28.90 & & & $30.49(7.82)$ & 30.6 & & 0.000 & $0.210^{3}$ \\
\hline WUP & Pre & $88.62(6.71)$ & 89.27 & & $0.075^{2}$ & $89.97(5.99)$ & 91.5 & & $0.110^{1}$ & $0.131^{3}$ \\
\hline W Пк & Post & $89.10(4.51)$ & 89.70 & 39 & 0.925 & $91.67(5.39)$ & 92.1 & 40 & 0.110 & $0.030^{3}$ \\
\hline$T C(\mathrm{moldd})$ & Pre & $109.03(28.67)$ & 102.89 & & $004=2$ & $143.43(19.67)$ & 142.8 & & 0,101 & $0.000^{4}$ \\
\hline $\mathrm{lc}(\mathrm{mg} / \mathrm{dI})$ & Post & $108.77(18.86)$ & 102.75 & 30 & 0.845 & $145.46(15.58)$ & 146.9 & 31 & 0.048 & $0.000^{4}$ \\
\hline & Pre & $19.13(5.59)$ & 19.51 & & & $20.62(17.57)$ & 16.1 & & & $0.284^{4}$ \\
\hline HDL (mg/di) & Post & $19.18(3.65)$ & 19.14 & 35 & $0.8 / 4$ & $20.30(4.34)$ & 19.4 & 31 & 0.010 & $0.253^{3}$ \\
\hline & Pre & $79.59(27.96)$ & 72.35 & & $0720^{2}$ & $99.27(21.18)$ & 99.6 & & 2000 & $0.000^{4}$ \\
\hline $\mathrm{LDL}(\mathrm{mg} / \mathrm{dl})$ & Post & $76.71(18.33)$ & 70.14 & 34 & $0.739^{2}$ & $103.79(14.19)$ & 103.5 & 37 & $0.358^{1}$ & $0.000^{4}$ \\
\hline$T C$ & Pre & $55.63(32.50)$ & 49.33 & & & $111.71(42.81)$ & 100.4 & & & $0.000^{4}$ \\
\hline 10 (III)/ (1) & Post & $63.92(31.74)$ & 56.68 & & 0.001 & $106.02(43.74)$ & 92.3 & ו & 0.100 & $0.000^{4}$ \\
\hline$C l=0$ ( & Pre & $95.55(11.48)$ & 97.47 & 26 & $0000^{2}$ & 77.43 (16.97) & 67.2 & & $0010^{2}$ & $0.000^{4}$ \\
\hline Uiucose (mimol/i) & Post & $99.55(13.61)$ & 102.51 & 30 & 0.009 & $79.11(16.78)$ & 70.7 & 37 & 0.014 & $0.000^{4}$ \\
\hline Ghrelin $(\mathrm{no} / \mathrm{ml})$ & Pre & $395.00(191.11)$ & 346.11 & & $0007^{2}$ & $416.70(210.48)$ & 389.6 & & $0070^{2}$ & $0.856^{4}$ \\
\hline & Post & $395.43(220.27)$ & 284.93 & & & $457.63(226.23)$ & 389.6 & & & $0.223^{4}$ \\
\hline & Pre & $23.87(11.05)$ & 24.21 & & & $30.65(12.01)$ & 29.2 & & & $0.028^{3}$ \\
\hline Adiponectin ( $\mu \mathrm{g} / \mathrm{mi})$ & Post & $22.46(10.16)$ & 24.65 & 27 & 0.554 & $36.45(21.41)$ & 35.0 & 33 & $0.0 / 8$ & $0.003^{4}$ \\
\hline & Pre & $17.44(14.55)$ & 13.29 & & $0-710^{2}$ & $24.42(17.03)$ & 22.1 & & & $0.103^{4}$ \\
\hline Lepim (ng/min) & Post & $18.44(17.28)$ & 13.82 & 21 & 0.710 & $25.19(23.29)$ & 15.5 & 35 & $0.4 / 2$ & $0.200^{4}$ \\
\hline
\end{tabular}

${ }^{1}$ Paired t-test; ${ }^{2}$ Wilcoxon test; ${ }^{3}$ T-test; ${ }^{4}$ Mann-Whitney test; SD = standard deviation; CI 95\%; BMI = body mass index; BF\% $=$ body fat percentage; SK = skinfold thickness; WHR $=$ waist-hip ratio; TC $=$ total cholesterol; HDL $=$ high-density lipoprotein cholesterol; $\mathrm{LDL}=$ low-density lipoprotein cholesterol; TG $=$ triglyceride. ${ }^{*}$ Comparison of the pre- and post-intervention data for each group. ${ }^{* *}$ Comparison of the pre- and post-intervention data between each group (control and intervention).

that in the explanatory model for ghrelin the significant variables were BMI and triglycerides (19.20\%). In the leptin model, the variable SK explained $25.30 \%$ of the variance for leptin. In the adiponectin model, the variables LDL and weight had an influence at a $10.80 \%$ level. The models' parameters were interpreted as follows:
Considering that in all cases the difference of the other variables is constant, for ghrelin, for every unit increased in the difference of BMI, there is a 43.23-unit increase in its difference, as well as for every unit increased in the difference of TG, there is a 1.67-unit decrease in its difference. For leptin, for every unit increased in the differ- 
Table 2. Results of the univariate models for the dependent variables adiponectin, leptin, and ghrelin for the control and intervention groups.

\begin{tabular}{|c|c|c|c|c|c|c|c|}
\hline Group & & Variables & Beta & Lower limit & Upper limit & $p$ value & Adjusted $\mathrm{R}^{2}$ \\
\hline \multirow{8}{*}{ Control } & \multirow{6}{*}{ Leptin } & Sex & -5.61 & -15.12 & 3.91 & 0.237 & 0.017 \\
\hline & & $\mathrm{BF} \%$ & 1.03 & -0.49 & 2.54 & 0.176 & 0.034 \\
\hline & & BMI & 7.78 & 2.74 & 12.81 & 0.004 & 0.251 \\
\hline & & SK & 0.93 & -0.58 & 2.43 & 0.216 & 0.022 \\
\hline & & $\mathrm{TC}$ & 0.211 & -0.014 & 0.44 & 0.064 & 0.092 \\
\hline & & Ghrelin & -0.02 & -0.053 & 0.009 & 0.157 & 0.040 \\
\hline & Adiponectin & HDL & 0.264 & -0.039 & 0.567 & 0.084 & 0.094 \\
\hline & Ghrelin & SK & 11.251 & -0.677 & 23.179 & 0.063 & 0.105 \\
\hline \multirow{8}{*}{ Intervention } & \multirow{3}{*}{ Leptin } & Weight & 3.505 & 0.770 & 6.239 & 0.014 & 0.159 \\
\hline & & SK & 2.290 & 0.912 & 3.668 & 0.002 & 0.253 \\
\hline & & $\mathrm{TC}$ & 0.466 & -0.556 & 1.487 & 0.359 & -0.004 \\
\hline & \multirow{2}{*}{ Adiponectin } & Weight & -1.845 & -5.106 & 1.416 & 0.257 & 0.010 \\
\hline & & LDL & 0.225 & -0.042 & 0.493 & 0.096 & 0.057 \\
\hline & \multirow{3}{*}{ Ghrelin } & BMI & 40.699 & -6.830 & 88.228 & 0.091 & 0.060 \\
\hline & & $\mathrm{TC}$ & 2.627 & -0.783 & 6.036 & 0.126 & 0.044 \\
\hline & & TG & -1.592 & -3.027 & -0.156 & 0.031 & 0.114 \\
\hline
\end{tabular}

$\mathrm{BMI}=$ body mass index; $\mathrm{BF} \%$ = body fat percentage; SK = skinfold thickness; $\mathrm{TC}=$ total cholesterol; $\mathrm{HDL}=$ high-density lipoprotein; $\mathrm{LDL}=$ low-density lipoprotein; $\mathrm{TG}=$ triglyceride .

Table 3. Results of the multivariate models of the control group for the dependent variables adiponectin, leptin, and ghrelin.

\begin{tabular}{|c|c|c|c|c|c|c|}
\hline \multirow{2}{*}{$\frac{\text { Model }}{{\text { Ghrelin }(\mathrm{DIF})^{*}}^{*}}$} & \multirow{2}{*}{$\begin{array}{c}\text { Variables } \\
\mathrm{SK}(\mathrm{DIF})^{*}\end{array}$} & \multirow{2}{*}{$\begin{array}{c}\text { Beta } \\
10.44\end{array}$} & \multicolumn{2}{|c|}{ CI 95\% Beta } & \multirow{2}{*}{$\begin{array}{c}\boldsymbol{p} \text { value } \\
0.063\end{array}$} & \multirow{2}{*}{$\begin{array}{c}\text { Adjusted R } \\
10.50 \%\end{array}$} \\
\hline & & & -0.68 & 23.17 & & \\
\hline & BMI $(\mathrm{DIF})^{*}$ & 8.53 & 4.27 & 12.80 & 0.000 & \\
\hline \multirow[t]{2}{*}{ Leptin (DIF) ${ }^{*}$} & SK $(\mathrm{DIF})^{*}$ & 1.33 & 0.23 & 2.47 & 0.020 & $47.60 \%$ \\
\hline & $\mathrm{TC}(\mathrm{DIF})^{*}$ & 0.24 & 0.07 & 0.41 & 0.008 & \\
\hline Adiponectin (DIF) $^{*}$ & HDL (DIF) $)^{*}$ & 0.30 & -0.04 & 0.57 & 0.084 & $9.40 \%$ \\
\hline
\end{tabular}

${ }^{*} \mathrm{DIF}=$ post-intervention data - pre-intervention data; $\mathrm{TC}=$ total cholesterol; $\mathrm{SK}=$ skinfold thickness; $\mathrm{BMI}=$ body mass index; $\mathrm{HDL}=$ high-density lipoprotein.

Table 4. Results of the multivariate models of the intervention group for the dependent variables adiponectin, leptin, and ghrelin.

\begin{tabular}{|c|c|c|c|c|c|c|}
\hline Models & Variables & Beta & \multicolumn{2}{|c|}{ CI 95\% Beta } & $p$ value & Adjusted $\mathbf{R}^{2}$ \\
\hline \multirow{2}{*}{ Ghrelin (DIF) $^{*}$} & BMI (DIF) ${ }^{*}$ & 43.23 & -0.95 & 87.42 & 0.055 & $19.20 \%$ \\
\hline & $\mathrm{TG}(\mathrm{DIF})^{*}$ & -1.67 & -3.03 & -0.28 & 0.020 & \\
\hline Leptin (DIF) ${ }^{*}$ & SK (DIF) ${ }^{*}$ & 2.29 & 0.91 & 3.67 & 0.002 & $25.30 \%$ \\
\hline \multirow{2}{*}{ Adiponectin (DIF) ${ }^{*}$} & $\operatorname{LDL}(\mathrm{DIF})^{*}$ & 0.28 & 0.01 & 0.54 & 0.044 & $10.80 \%$ \\
\hline & Weight (DIF) ${ }^{*}$ & -2.60 & -5.78 & 0.59 & 0.106 & \\
\hline
\end{tabular}

*DIF = post-intervention data - pre-intervention data; $\mathrm{CI}=$ confidence interval; $\mathrm{SK}=$ skinfold thickness; $\mathrm{BMI}=$ body mass index; $\mathrm{TG}=$ triglyceride; $\mathrm{LDL}=$ low-density lipoprotein. 
ence of SK, there is a 2.29-unit increase in its difference. For adiponectin, for every unit increased in the difference of LDL, there is a 0.28 -unit increase in its difference, as well as for every unit increased in the difference of weight, there is a 2.60 -unit decrease in adiponectin.

It can be seen in Table 5 that there was no significative difference in the pre- and post-intervention comparison in the control and intervention groups individually as well as in the comparison between the control and intervention groups in the pre-intervention period.

However, there was a significant difference when comparing the control and intervention groups in the post-intervention period for adiponectin $(p=0.002)$, which shows an upward trend in the proportion of subjects with higher plasma concentration of adiponectin in the intervention group in the post-intervention period compared to the control group.

\section{DISCUSSION}

The current study assessed the impact of a physical activity program on the levels of adiponectin, leptin, and ghrelin in children in public schools.

The analyses of the intervention on the plasma levels of these substances were based on two statistical methods for adjusting all possible models, thus increasing the explanatory ability of the models being studied with different numbers of variables. The models' explanations were not above $80 \%$ for both groups. That shows the variables were likely not enough to explain the impact of physical activity on ghrelin, leptin, and adiponectin. Only leptin had a high percentage of variance explained by the adjusted model, $\mathrm{R}^{2}=47.60 \%$ in the control group for the independent variables BMI, SK, and TC, and $\mathrm{R}^{2}=$ $25.30 \%$ in the intervention group for SK. Studies have shown that leptin levels may be partially related to the size of the body's fatty tissue, and they also suggest that the increase in fatty tissue raises serum levels of leptin through mechanisms involving the number of fatty cells and the induction of ob mRNA [21-23]. Nevertheless, the serum level of leptin does not depend only on the size of the fatty tissue; other mechanisms seem to be involved in regulating its production [24-26].

Among the explanatory variables in the model for ghrelin (BMI, TG, and SK), studies suggest their main roles are regulating food intake and energetic balance by the hypothalamic centers [27,28]. However, a possible relation between changes in body make-up and ghrelin plasma levels has not been well established by the literature. The variations in plasma ghrelin levels are mainly regulated by the intake of certain nutrients. Ingesting animal protein and lipids raises such levels. However, an increase in plasma insulin also suggests changes in ghrelin levels [29-32]. Further studies are needed to try to explain this mechanism.

When comparing both groups in the post-intervention group for the variables adiponectin, leptin, and ghrelin, a

Table 5. Results of the comparisons of the pre- and post-intervention periods of the control and intervention groups, individually and between groups.

\begin{tabular}{|c|c|c|c|c|c|c|c|c|c|}
\hline & & \multicolumn{3}{|c|}{ Control } & \multicolumn{3}{|c|}{ Intervention } & \multirow{2}{*}{$p^{2}$} & \multirow{2}{*}{$p^{3}$} \\
\hline & & Pre & Post & $p^{1}$ & Pre & Post & $p^{1}$ & & \\
\hline \multirow{4}{*}{ Adiponectin } & $\leq 20.02$ & 7 & 10 & 0.504 & 6 & 7 & 0.416 & 0.072 & 0.002 \\
\hline & $>20.02, \leq 26.03$ & 11 & 9 & & 7 & 3 & & & \\
\hline & $>26.03, \leq 37.15$ & 5 & 6 & & 10 & 10 & & & \\
\hline & $>37.15$ & 4 & 2 & & 10 & 13 & & & \\
\hline \multirow{4}{*}{ Leptin } & $\leq 6.91$ & 7 & 7 & 0.240 & 7 & 10 & 0.215 & 0.067 & 0.505 \\
\hline & $>6.91, \leq 15.51$ & 4 & 10 & & 11 & 9 & & & \\
\hline & $>15.51, \leq 29.66$ & 9 & 8 & & 5 & 6 & & & \\
\hline & $>29.66$ & 12 & 7 & & 4 & 2 & & & \\
\hline \multirow{4}{*}{ Ghrelin } & $<232.46$ & 8 & 12 & 0.587 & 9 & 5 & 0.206 & 0.518 & 0.163 \\
\hline & $>232.46, \leq 381.94$ & 8 & 4 & & 5 & 10 & & & \\
\hline & $>381.94, \leq 565.93$ & 6 & 5 & & 11 & 9 & & & \\
\hline & $>565.93$ & 6 & 7 & & 8 & 9 & & & \\
\hline
\end{tabular}

${ }^{1}$ McNemar-Bowker's test when comparing pre and post-intervention values in the control and intervention groups, individually; ${ }^{2}$ Exact Pearson's chi-square test when comparing the control and intervention groups in the pre-intervention period; ${ }^{3}$ Exact Pearson's chi-square test when comparing the control and intervention groups in the post-intervention period. 
significant difference $(p=0.002)$ was found for adiponectin, which shows an increase in the proportion of subjects with higher plasma adiponectin levels for the intervention group. At the same time, a reduction was found in $\mathrm{BMI}$ and $\mathrm{BF} \%$ for the children in this group. Similar results were found in a study by Reinehr et al. [33] with 42 obese children, 10.2 years old on average, subjected to a physical activity intervention program for one year. The authors found a strong association between the higher adiponectin levels and weight loss (lower BMI) in the group studied with average adiponectin levels of $12.2 \mathrm{ng} / \mathrm{ml}$. Cambuli et al. [34] found a $245 \%$ increase in serum adiponectin levels along with weight loss in 48 obese children after one year. On the other hand, MartosMoreno et al. [35] suggests that not only the amount of body fat, but also the maturity of the fatty tissue, may play a key role on the serum adipocytokine profile in children. In another study, no change in adiponectin levels was found in 49 children eight to 17 years old who underwent a four-week exercise program [36]. An eightweek randomized study with 20 obese children $10.8 \pm$ 0.67 years old showed that, with no weight loss or changes in body make-up, there was no significant change in adipocytokine levels [37]. The mechanisms of serum adiponectin level regulation have not been fully explained and its expression may vary according to the distribution of fatty tissue, sensibility to insulin, glycolcorticoids, triglyceride, TNF- $\alpha$, IL- 6 , and puberty [3840].

Regarding the body make-up, there was no significant difference between the groups evaluated for the variables $\mathrm{BMI}$ and $\mathrm{BF} \%$ by the end of the study. However, the values of both variables decreased in the post-intervention period for the intervention group and increased for the control group, which was significant for the BMI $(p=$ 0.001). Jiang et al. [41], in a randomized clinical trial with 2425 students $8.4 \pm 1.4$ years old in Beijing, China, who underwent a three-year physical activity and food re-education intervention program, reported that the prevalence of overweight and obesity decreased in the study population and that strategies for involving the parents with the program should be prioritized in future researches. Maintaining a moderate-to-rigorous physical activity program for over three years in overweight children is likely to significantly reduce BMI. However, the small change in BMI associated to changes in the amount of physical activity may explain the disappointing results of BMI reduction in short-term interventions [42]. In a meta-analysis on the effectiveness of weight reduction in children, Snethen et al. [43] concluded that combining variables such as diet, physical activity, changes in habits, and family involvement may be effective in reducing children's weight, but the data found were not enough to show which variable is the most effective.
The intervention program in the current study had moderate-intensity physical activity. According to the literature, moderate activity is an appropriate level of caloric expenditure for children at the age group followed, since high-intensity activities are not advised due to the risks of overloading both the cardiovascular and musculoskeletal system, making them prone to injuries [44-47]. Aerobic exercises are the most suitable for weight loss and reduction in metabolic changes in overweight and obese children [48], being 30 to 40 minutes of physical activity three times a week the suggested amount $[49$, 50].

Despite its health benefits of reduction and prevention of overweight and obesity, the adherence to regular physical activity faces facilities availability barriers as well as behavioral, economic, and social [51]. The difficulty in available public and private facilities for developing the physical activities included in this study, as well as matching the time of exercise and transport, may be considered barriers for children to adhere to the activities and to continue the program. In the present investigation, an expressive adherence to the program by the children was seen over the four-month physical activity period. However, it is worth pointing out the difficulty found during the lecture program for both the control and intervention groups, in which considerable parents' adherence was not seen. Factors such as night-shift work, incompatibility of times and dates of the meetings, and personal interest seem to have been the greatest barriers for the parents' adherence to the program.

\section{CONCLUSION}

The impact of the intervention program on the plasma levels of adiponectin, leptin, and ghrelin was positive in raising adiponectin levels associated with a reduction in $\mathrm{BMI}$ and $\mathrm{BF} \%$. However, the models for the variables adiponectin, leptin, and ghrelin had a low explanatory ability in the adjusted models. Therefore, further analysis of other factors that might influence the results is needed.

\section{ACKNOWLEDGEMENTS}

Research supported by International Atomic Energy Agency (IAEA), Acuerdo Regional de Cooperaciónpara la Promoción de la Ciencia y la Tecnologia Nuclearesem America Latina y el Caribe (ARCAL) RLA 6/059, Foundation for Research Support of the State of Minas Gerais (FAPEMIG), Research Program of the National Health Service (PPSUS) 3282/06, National Council of Scientific and Technological Development $(\mathrm{CNPq})$. The authors would like to thank the staff of this project and the children and parents who participated in this trial.

\section{REFERENCES}

[1] Pénicaud, L., Cousin, B., Leloup, C., Lorsignol, A. and 
Casteilla, L. (2000) The autonomic nervous system, adipose tissue plasticity, and energy balance. Nutrition, 16, 903-908. http://dx.doi.org/10.1016/S0899-9007(00)00427-5

[2] Saleh, J., Sniderman, A.D. and Cianflone, K. (2000) Regulation of plasma fatty acid metabolism. Clinica Chimica Acta, 286, 163-180.

http://dx.doi.org/10.1016/S0009-8981(99)00099-6

[3] Ahima, R.S. and Flier, J.S. (2000) Adipose tissue as an endocrine organ. Trends in Endocrinology and Metabolism, 11, 327-332.

http://dx.doi.org/10.1016/S1043-2760(00)00301-5

[4] Arsian, N., Baris, E. and Aydin, A. (2010) Hormones and cytokines in childhood obesity. Indian Pediatrics, 47, 829-839. http://dx.doi.org/10.1007/s13312-010-0142-y

[5] Ebbeling, C.B., Rawlak, D.B. and Ludwig, D.S. (2002) Childhood obesity: Public-health crisis, common sense cure. Lancet, 360, 473-482. http://dx.doi.org/10.1016/S0140-6736(02)09678-2

[6] Saelens, B.E., Grow, H.M., Stark, L.J., Seeley, R.J. and Roehrig, H. (2011) Efficacy of increasing physical activity to reduce children's visceral fat: A pilot randomized controlled trial. International Journal of Obesity, 6, 102112. http://dx.doi.org/10.3109/17477166.2010.482157

[7] Lloyd, L.J., Langley-Evans, S.C. and McMullen, S. (2012) Childhood obesity and risk of the adult metabolic syndrome: A systematic review. International Journal of Obesity, 36, 1-11. http://dx.doi.org/10.1038/ijo.2011.186

[8] Ruchatand, S.M. and Mottola, M.F. (2012) Preventing long-term risk of obesity for two generations: Prenatal physical activity is part of the puzzle. Journal of Pregnancy, 2012, 1-33. http://dx.doi.org/10.1155/2012/470247

[9] Steen, S.N. (1994) Nutrition for young athletes: Special considerations, Sports Medicine, 17, 152-164. http://dx.doi.org/10.2165/00007256-199417030-00002

[10] Summerbell, C.D., Waters, E., Edmunds, L.D., Kelly, S., Brown, T. and Campbell, K.J. (2005) Interventions for preventing obesity in children. The Cochrane Database of Sistematic Reviews, 20, 1-70.

[11] Garrow, J.S. and Webster, J. (1985) Quetelet's index (W/ $\mathrm{H}^{2}$ ): As a measure of fatness. International Journal of Obesity, 9, 147-153.

[12] De Onis, M., Onyango, A.W., Borghi, E., Siyam, A., Nishida, C. and Siekmann, J. (2007) Development of a WHO growth reference for school-aged children and adolescents. Bulletin of the World Health Organization, 85, 660-667. http://dx.doi.org/10.2471/BLT.07.043497

[13] Taylor, R.W., Jones, I.E., Williams, S.M. and Goulding, A. (2000) Evaluation of waist circumference, waist-to-hip ratio, and conicity index as screening tools for high trunk fat mass, as measures by dual-energy by dual-energy X-ray absorptiometry, in children aged 3-19 y. The American Journal of Clinical Nutrition, 72, 490-495.

[14] Heyward, V.H. and Stolarczyl, L.M. (2000) Avaliação da composição corporal. Manole, São Paulo, 243 p.

[15] Slaughter, M.H., Lohman, T.G., Boileau, R.A. et al. (1988) Influence of maturation on relationship of skinfold to body density: A cross-sectional study. Human Biology, 56, 681-689.
[16] Friedewald, W.T., Levy, R.I. and Fredrickson, D.S. (1972) Estimation of the concentration of low-density lipoprotein cholesterolin plasma, without use of the preparative ultracentrifuge. Clinical Chemistry, 18, 499-502.

[17] Ferguson, M.A., White, L.J., McCoy, S., Kim, H.W., Petty. T. and Wilsey, J. (2003) Plasma adiponectin response to acute exercise in health subjects. European Journal of Applied Physiology, 91, 324-329. http://dx.doi.org/10.1007/s00421-003-0985-1

[18] Koistinen, H.A. Tominen, J.A. Ebeling, P., Heiman, M.L., Stephens, T.W. and Koivisto, V.A. (1998) The effect of exercise on leptin concentration in health men and type 1 diabetic patients. Medicine and Science in Sports and Exercise, 30, 805-810. http://dx.doi.org/10.1097/00005768-199806000-00005

[19] Foster-Schubert, K. Mctiernan, A. Frayo, S., et al. (2005) Human plasma ghrelin levels increase during a one-year exercise program. The Journal of Clinical Endocrinolology and Metabolism, 90, 820-825.

[20] Verhagen, A., De Vet, H., De Bie, R., et al. (1998) The Delphi list: A criteria list for quality assessment of randomized clinical trials for conduction systematic reviews developed by Delphi consensus. Journal of Clinical Epidemiology, 51, 1235-1241. http://dx.doi.org/10.1016/S0895-4356(98)00131-0

[21] Friedmann J.M. and Halaas, J.L. (1998) Leptin and the regulation of body weight in mammals. Nature, 395, 763-770. http://dx.doi.org/10.1038/27376

[22] Sandoval, D.A. and Davis, S.N. (2003) Leptin: Metabolic control and regulation. Journal of Diabetes and Its Complications, 17, 108-113. http://dx.doi.org/10.1016/S1056-8727(02)00167-8

[23] Considine, R.V., Sinha, M.K., Heiman, M.L., et al. (1996) Serum immunoreactiveleptin concentrations in normalweight and obese humans. The New England Journal of Medicine, 334, 292-295. http://dx.doi.org/10.1056/NEJM199602013340503

[24] Maffei, M.J., Haalas, J., Ravussin, E., et al. (1995) Leptin levels in humans and rodent: measurement of plasma leptin and ob RNA in obese and weight-reduced subjects. Nature Medicine, 11, 1155-1161. http://dx.doi.org/10.1038/nm1195-1155

[25] Leyva, F., Godsland, I.F., Ghatei, M., et al. (1998) Hyperleptinemia as a component of a metabolic syndrome of cardiovascular risk. Arteriosclerosis, Thrombosis and $\mathrm{Va}$ scular Biology, 18, 928-933. http://dx.doi.org/10.1161/01.ATV.18.6.928

[26] Vierhapper, H., Heinze, G., Nowotny, P. and Bieglmayer, C. (2003) Leptin and the control of obesity. Metabolism, 52, 379-381. http://dx.doi.org/10.1053/meta.2003.50059

[27] Nakazato, M., Murakami, N., Date, Y., et al. (2001) A role for ghrelin in the central regulation of feeding. $\mathrm{Na}$ ture, 409, 194-198. http://dx.doi.org/10.1038/35051587

[28] Ukkola O. and Poykoo, S. (2002) Ghrelin, growth and obesity. Annals of Medicine, 34, 102-108. http://dx.doi.org/10.1080/07853890252953491

[29] Rosicka, M., Krsek, M., Matoulek, Z., et al. (2003) Serum ghrelin levels in obese patients: The relationship to 
serum leptin levels and soluble leptin receptors levels. Physiology Research, 52, 61-66.

[30] Leidy, H.J., Mattes, M.R. and Campbell, W.W. (2007) Effects of acute and chronic protein intake on metabolism, appetite, and ghrelin during weight loss. Obesity, 15, 12151225. http://dx.doi.org/10.1038/oby.2007.143

[31] Salbe, A.D., Tshop, M.H., Delparigi, A., Venti, C. and Tataranni, P.A. (2004) Negative relationship between fasting plasma ghrelin concentrations and ad libitum food intake. The Journal of Clinical Endocrinolology and Metabolism, 89, 2951-2956.

http://dx.doi.org/10.1210/jc.2003-032145

[32] Erdmann, J., Topsch, R., Lippl, F., Gussmann, P. and Schusdziarra, V. (2004) Postprandial response of plasma ghrelin levels to various test meals in relation to food intake, plasma insulin, and glucose. The Journal of Clinical Endocrinolology and Metabolism, 89, 3048-3054. http://dx.doi.org/10.1210/jc.2003-031610

[33] Reinehr, T., Roth, C., Menke, T. and Andler, W. (2004) Adiponectin before and after weight loss in obese children. The Journal of Clinical Endocrinolology and Metabolism, 89, 3790-3794.

http://dx.doi.org/10.1210/jc.2003-031925

[34] Cambuli, V.M., Musiu, M.C., Incan, M., et al. (2008) Assessment of adiponectin and leptin as biomarkers of positive metabolic outcomes after lifestyle intervention in overweight and obese children. The Journal of Clinical Endocrinolology and Metabolism, 93, 3051-3057. http://dx.doi.org/10.1210/jc.2008-0476

[35] Martos-Moreno, G.A., Barrios, V., Martínez, G., Hawkins, F. and Argente, J. (2010) Effect of weight loss on high-molecular weight adiponectin in obese children. Obesity, 18, 2288-2294.

http://dx.doi.org/10.1038/oby.2010.68

[36] Mauras, N. et al. (2008) Adiponectin and catecholamine concentrations during acute exercise in children with type 1 diabetes. Pediatric Diabetes, 9, 221-227.

[37] Kelly, A.S., Steinberger, J., Olson, T.P. and Dengel, D.R. (2007) In the absence of weight loss, exercise training does not improve adipokines or oxidative stress in overweight children. Metabolism: Clinical and Experimental, 56, 1005-1009.

http://dx.doi.org/10.1016/j.metabol.2007.03.009

[38] Beltowski, J. (2003) Adiponectin and resistin: New hormones of white adipose tissue. Medical Science Monitor: International Medical Journal of Experimental and Clinical Research, 9, 55-61.

[39] Bruun, J.M., Lihn, A.S., Verdich C., et al. (2003) Regulation of adiponectin by adipose tissue-derived cytokines: In vivo and in vitro investigations in humans. American Journal of Physiology. Endocrinology and Metabolism, 285, 527-533.
[40] Ronti, T., Lupattelli, G. and Mannarino, E. (2006) The endocrine function of adipose tissue: An update. Clinical Endocrinology, 64, 355-365.

[41] Jiang, J., Xia, X., Greiner, T., Wu, G., Lian, G. and Rosenqvist, U. (2007) The effects of a 3-year obesity intervention in schoolchildren in Beijing. Child: Care, Health and Development, 33, 641-646. http://dx.doi.org/10.1111/j.1365-2214.2007.00738.x

[42] Trinh, A., Campbell, M., Ukoumunne, O.C., Gerner, B. and Wake, M. (2013) Physical activity and 3-year BMI change in overweight and obese children. Pediatrics, 131, e470-e477.

[43] Snethen, J.A., Broome, M.E. and Cashin, S.E. (2006) Effective weight loss for overweight children: A meta-analysis of intervention studies. Journal of Pediatric Nursing, 21, 45-66. http://dx.doi.org/10.1016/j.pedn.2005.06.006

[44] American College of Sports Medicine (2006) Guidelines for exercises testing and prescription. 7th Edition, Lippincott Williams \& Wilkins, Philadelphia.

[45] Hill, J.O. and Wyatt, H.R. (2005) Role of physical activity in preventing and treating obesity. Journal of Applied Physiology, 99, 765-770. http://dx.doi.org/10.1152/japplphysiol.00137.2005

[46] Physical Activity Guidelines Advisory Committee (2008) Physical activity guidelines advisory committee report. Department of Health and Human Services, Washington DC.

[47] Baumer, J.H. (2007) Guideline review: Obesity and overweight: Its prevention, identification, assessment and management. Archives of Disease in Childhood. Education Practice edition, 92, 92-96. http://dx.doi.org/10.1136/adc.2007.118448

[48] Strong, W.B., Malina, R.M., Blimkie, C.J.R., et al. (2005) Evidence based physical activity for school-age youth. Journal of Pediatric, 146, 732-737. http://dx.doi.org/10.1016/i.jpeds.2005.01.055

[49] Andersen, L., Harro, M., Sardinha, L., et al. (2006) Physical activity and clustered cardiovascular risk in children: A cross sectional study-The european youth heart study. Lancet, 368, 299-304. http://dx.doi.org/10.1016/S0140-6736(06)69075-2

[50] Nowicka, P. and Flodmark, C.E. (2006) Physical activitykey issues in treatment of childhood obesity. Acta Paediatrica Supplement, 96, 39-45.

[51] Martins, C., Morgan, L. and Truby, H. (2008) A review of the effects of exercise on appetite regulation: An obesity perspective. International Journal of Obesity, 32, 1337-1347. http://dx.doi.org/10.1038/ijo.2008.98 